\title{
Process Democracy
}

\author{
Kevin Vallier \\ Philosophy Department, Bowling Green State University, \\ Bowling Green, Ohio, USA \\ kevinvallier@gmail.com
}

\begin{abstract}
Democratic theorists have proposed a number of competing justifications for democratic order, but no theory has achieved a consensus. While expecting consensus may be unrealistic, I nonetheless contend that we can make progress in justifying democratic order by applying competing democratic theories to different stages of the democratic process. In particular, I argue that the selection of political officials should be governed in accord with aggregative democracy. This process should prize widespread participation, political equality, and proper preference aggregation. I then argue that the selection of public policies by political officials should be governed in accord with deliberative democracy. This process should prize high quality deliberation and political equality. A process democracy is a democracy that joins an aggregative process for selecting officials with a deliberative process for selecting policies. Democracy is justified and legitimate when it is structured in this way.
\end{abstract}

\section{Keywords}

democracy - deliberative democracy - aggregative democracy - democratic legitimacy - political legitimacy

A central aim of democratic theory is to determine whether citizens ought to be governed democratically. Democratic theorists have proposed a number of competing justifications for democratic order, but no theory has achieved a consensus. While expecting consensus in political philosophy may be unrealistic, I contend that we can make progress in justifying democratic order by applying competing democratic theories to different stages of the democratic process. Much as deliberative democrats have begun to consider how a political 
system might be deliberative as a whole without necessarily being deliberative in each part, I argue that we can justify the democratic process on the grounds that each part of the democratic process can realize the distinct values characteristic of the main justifications for democratic governance. ${ }^{1}$

To restrict my focus, I will engage two main theoretical traditions: deliberative democracy ${ }^{2}$ and aggregative democracy. ${ }^{3}$ Roughly, deliberative democracy claims that democracy is justified when it is equal and adequately deliberative. The use of political power is appropriate when it is the outcome of high-quality deliberation among citizens and political officials with equal power. Aggregative democracy claims that democracy is justified when it is equal and has extensive participation that is properly aggregated. The use of political power is appropriate when citizens feed their preferences over candidates and policies into a rational and morally attractive voting system.

I will apply deliberative and aggregative democracy to two stages of the democratic process: the selection of officials by the public, and the selection of public policies by those officials. I argue that the selection of officials should prioritize the values of participation and political equality, whereas policy choice should prioritize the values of deliberation and political equality. In short, official selection should function as an aggregative democracy, whereas policy choice should function as a deliberative democracy. A process democracy conjoins these institutional forms; and a process democratic theory holds that democracy is justified when different stages of the democratic process each realize distinct democratic values.

1 For a recent survey of work in the systemic turn, see Owen, David, and Graham Smith. 2015. "Deliberation, Democracy, and the Systemic Turn." Journal of Political Philosophy 23, 213-234.

2 Classic works of deliberative democracy are many, but some of the main monographs and articles can be found in the following works: Habermas, Jurgen. 1998. Between Facts and Norms: Contributions to a Discourse Theory of Law and Democracy. Translated by William Rehg. New York: Miт Press, Bohman and Rehg 1998, Gutmann, Amy, and Dennis Thompson. 2004. Why Deliberative Democracy? Princeton: Princeton University Press and Freeman, Samuel. 200o. "Deliberative Democracy: A Sympathetic Comment." Philosophy and Public Affairs 29, 371-418. Bowman, James and Henry Richardson. 2009. "Deliberative Democracy, Liberalism, and Reasons That All Can Accept." Journal of Political Philosophy 17, 1-22. Also see Parkinson and Mansbridge 2012.

3 Theorists often associated with aggregative democracy include Schumpeter (1942) and Downs, Anthony (1957). An Economic Theory of Democracy. New York: Harper, Riker (1988) and Dahl, Robert (1989). Democracy and Its Critics. New Haven: Yale University Press. Riker articulates some principles of "fairness" that include the Pareto principle and the universal admissibility of different preference orderings in Riker (1988, pp. 116-7). 
Process democracy also furnishes an account of democratic legitimacy, that is, when democratic governance can impose duties on its citizens. ${ }^{4}$ Deliberative democrats claim that the democratic process is legitimate when it proceeds according to high-quality public deliberation between equal citizens. ${ }^{5}$ Aggregative democrats have said much less about legitimacy, but their approach suggests that the democratic process is legitimate when it feeds enough data about citizens' preferences into rationally and morally attractive voting rules. Process democracy combines the virtues of both theories by holding, first, that the selection of officials is legitimate when it is adequately equal and appropriately aggregates the preferences of citizens, and second, that policy choice is legitimate when it is adequately equal and results from high-quality deliberation. Both aggregative and deliberative democrats are right about part of the democratic process, but neither is correct for democracy as a whole.

Thus, the general aim of this paper is to show that we can make progress in determining how to justify democracy by using competing democratic theories to justify and legitimize different parts of the democratic process. The specific aim of the paper is to justify and legitimize an aggregative approach to the selection of political officials and a deliberative approach to the selection of public policy. Both aims are novel because, thus far, democratic theorists have developed democratic theories to justify democratic theories as a whole, rather than indexing democratic theories to stages of the democratic process.

This essay is a work of non-ideal theory in the sense that it evaluates democratic institutions in light of the cognitive and motivational limitations of citizens, special interest groups, and political officials. It is also a work of non-ideal theory because it recognizes that normally functioning democratic institutions cannot simultaneously realize all the values of democratic procedures. An ideal theorist might defend a choice between democratic theories by assuming that these theories govern institutional and social contexts under which all democratic values can be fully realized. I think that it is better to face up to trade-offs between democratic values and grapple with problems such as voter ignorance and institutional capture because we can vindicate the use of

4 Here I follow John Simmons' well-known distinction between justification and legitimacy; as noted, justification determines when a democratic state morally should govern its citizens; but legitimacy, at least for many, determines when the democratic state can legitimately impose duties on its citizens. For further discussion, see Simmons, A. John (1999). "Justification and Legitimacy." Ethics 109, 739-771.

5 The term "deliberative democracy" actually tends to denote a theory of legitimacy and democratic institutional structure, rather than a theory of what makes democracy justified, but I will focus first on justification and then on legitimacy. 
democratic procedures under less than favorable conditions. That is not to say that ideal theory is unimportant or inappropriate. ${ }^{6}$

In Section I, I outline central democratic values, focusing on conceptions of participation, deliberation, and political equality. I also explain the tradeoffs between them. Section II argues that the selection of political officials should realize the values of participation and equality, in line with aggregative democracy. Section III argues that policy choice should realize the values of deliberation and equality, in line with deliberative democracy. Section IV addresses two objections to my hybrid account of democratic justification. Section $\mathrm{v}$ develops a process democratic account of legitimacy and contrasts it with deliberative and aggregative approaches.

\section{Democratic Values and Trade-Offs}

Democratic theorists argue that democratic processes can be justified because democratic processes realize a range of political values. To simplify, I will focus on the political values of deliberation, participation, and equality. James Fishkin develops conceptions of these values that, in my view, have two advantages. First, they are sufficiently specific to explain why institutional design requires making trade-offs between these values. Second, they are sufficiently general to explicate and motivate a process democratic approach to justifying democratic institutions. ${ }^{7}$

(1) Fishkin understands deliberation as "the process by which individuals sincerely weigh the merits of competing arguments in discussions together." Deliberation looks to achieve a certain level of quality, such that good legislative and policy options can be decided upon. The goal of deliberation is to realize five values: information, substantive balance, diversity, conscientiousness, and equal consideration..$^{9}$ Information should be reasonably accurate; arguments should be offered by different perspectives to achieve balance; viewpoints should be diverse to represent the diverse views among the public; participants should conscientiously evaluate arguments; and each person's arguments should be given equal consideration. Deliberation is, at the least, an epistemic value. It helps democracies to make informed decisions. But

6 For a recent overview of ideal/nonideal theory debates, see Vallier, Kevin and Michael Weber, eds. (2017). Political Utopias: Contemporary Debates. New York: Oxford University Press.

7 Fishkin, James. (2009). When the People Speak: Deliberative Democracy and Public Consultation. Oxford: Oxford University Press, pp. 46, 6 o.

8 Ibid., p. 33 .

9 Ibid., p. 34 . 
deliberation can also have moral value insofar as engaging in a deliberative process with other citizens has moral worth in itself.

(2) For Fishkin, participation occurs when the bulk of the population engages in the political process. ${ }^{10}$ Political participation can be understood more specifically as "behavior on the part of members of the mass public directed at influencing, directly or indirectly, the formulation, adoption, or implementation of governmental or policy choices." ${ }^{\text {11 }}$ Participation includes many activities, from writing letters to one's representative, to taking part in demonstrations, signing petitions, publishing editorials, and organizing getout-the-vote efforts. Participation, like deliberation, seems to have both epistemic and moral value. It can increase the quality of democratic decisions, but also express the moral value of a shared democratic life and the goodness of being part of the democratic process.

(3) Fishkin defines political equality as "the equal consideration of political preferences." ${ }^{\prime 2}$ Each person's preference or choice should be counted the same, given equal weight. Political equality is typically realized through a one person, one vote standard, where each member of the public is given one and only one vote over the relevant issues and has an equal opportunity to affect the political process. But Fishkin stresses the indeterminacy of the idea of political equality because equality is neutral between one man, one vote, and "microcosmic experiments" where deliberative bodies are chosen through a random selection mechanism from the public, such that the public's views are addressed in discussion among representative persons.

I will understand political equality in a general way as the equal representation of interests or viewpoints in politically competitive conditions where persons have roughly equal influence on political decisions. ${ }^{13}$ Thus, political equality as such doesn't require that each person have a vote, just that his or her interests or perspectives are be considered and treated equally.

Ideally, we want democratic procedures that fully realize deliberation, participation, and equality. But in non-ideal theory of the sort I pursue here, we must weigh these political values against one another in designing democratic institutions. The primary reason for this is that ordinary people have limited time to reflect and deliberate about how to vote.

If we want everyone to participate in the democratic process, we will have to forgo high-quality deliberation, given that most people are unable and often

\footnotetext{
10 Ibid., p. 45 .

11 Ibid.

12 Ibid., p. 43.

13 Ibid., p. 44.
} 
unwilling to engage in the complex learning process required to deliberate well. If we want high-quality deliberation, we must forgo mass participation and instead accept that deliberation will occur primarily among a small subset of the population. We may be able to design deliberation so that deliberators are at least representative of the population, and so equally represent and consider everyone's interests, but participation is still sacrificed. The history of democratic practice illustrates the trade-off between participation and deliberation; as Fishkin argues, there has "never ... been an institution that reliably delivered political equality, deliberation, and mass participation simultaneously."14

Fishkin argues that overcoming this limitation is likely to be extremely expensive and infeasible, such as holding national Deliberation Days of the sort Fishkin has proposed elsewhere. ${ }^{15}$ It might be possible to realize all three values through compulsion, but the necessary compulsion would be so great that it will conflict with personal liberty. ${ }^{16}$ Compulsory voting may not be excessively restrictive, but compulsory deliberation is far more invasive.

To combine adequate participation and deliberation, we might consider giving up political equality. One way this might be done is to give everyone an incentive to take part in deliberative forums, and then, if only a tiny, unrepresentative minority shows up, allow them to make political decisions. Fishkin calls this "enclave deliberation" and he rightly worries that such deliberation will "by its very nature attract partisans or even true believers" and so is unlikely to be representative of public opinion. ${ }^{17}$ The deliberating minority is especially unlikely to represent underprivileged and marginalized groups who, due to a history of oppression, may feel sufficiently discouraged by the political process that they do not participate.

I will take for granted that political equality is the most essential of the three values. Unequal systems lack even the most basic justification and legitimacy, whereas systems with lower-quality participation and deliberation are flawed, but raise fewer fundamental complaints. Because this essay is a work of non-ideal theory, I will proceed under the assumption that participation and deliberation are in conflict with one another but I will assume that equality is non-negotiable.

If we accept that institutions must trade-off participation and deliberation, we can envision how democratic systems that stress participation will differ from democratic systems that stress deliberation. Participatory democracies

\footnotetext{
14 Ibid., p. 47 .

15 Ibid., p. 46.

16 Ibid., p. 54.

17 Ibid., p. 53 .
} 
will focus on encouraging people to vote under equal conditions but will not expend great effort to increase the quality of deliberation in regard to the choice of officials or policies. Such a democracy will instead focus on directly and frequently consulting as many citizens as possible, and ensuring that their input informs decisions. Consultations will both shape the substance of which representatives and policies should be chosen and help citizens form and change their views. ${ }^{18}$ Participatory processes will have the moral attraction of being based on an attempt to establish mass consent. We can also hope that participatory democracy will also hopefully educate ordinary citizens as well as consult them.

Deliberative democratic systems realize political equality through representative deliberation rather than mass participation. ${ }^{19}$ Participatory democracy is vulnerable to the fact that rich and highly educated citizens participate most often, and we typically do not want to compel voting and discussion to compensate. ${ }^{20}$ But deliberative systems can avoid this problem with microcosmic deliberation, where, again, persons are selected at random from the populate and then placed in face-to-face discussion. ${ }^{21}$ These individuals are given information about a policy choice and engage in structured deliberation; they are then given equal voting rights and vote on a proposed public policy. If citizens are randomly selected and have equal voting rights, they should tend to represent a cross-section of the public and not just the most informed and wealthy citizens; the resulting policy choice will mirror what the populace would have chosen under similarly informed and reflective circumstances. A random sample of voters can serve as a proxy for the preferences of the public as a whole.

Some may worry that citizens are treated unequally when only a small number of citizens participate in public deliberation; on this view, equality cannot be realized without mass participation. But everyone still has voting rights in the scenario I've outlined, so all are allowed to participate. Everyone already has the power to influence the democratic process, so these small publics will not violate equality, provided we do not restrict electoral rights and that choosing deliberators through random sampling leads to representing an appropriate

18 Fishkin (2009, p. 77).

19 Deliberative democracy has many advocates. For what continues to be a nice range of views, see Bohman, James, and William Rehg, eds. (1998). Deliberative Democracy: Essays on Reason and Politics. New York: MIT Press, especially the articles by Joshua Cohen, Rawls, and Habermas. For a recent update on the state of deliberative democratic theory, see Parkinson, John, and Jane Mansbridge, eds. (2012). Deliberative Systems: Deliberative Democracy at the Large Scale. Cambridge: Cambridge University Press.

20 Fishkin (2009, p. 80).

21 Ibid., p. 82. 
cross-section of public opinion. Microcosmic deliberation is inferior from the perspective of political equality than equivalent acts of macrocosmic deliberation. But given that we must choose between participation and deliberation in institutional design, the best way to realize equality in deliberation while ensuring high quality is through random sampling.

As I have noted, two of the main stages of the democratic process are choosing officials and choosing policies. These stages involve different groups. Officials are chosen by the public as a whole, or by sectors of the public, or other officials, whereas the officials themselves are usually the only people involved in policy choice. Both stages can prioritize participation or deliberation. In the case of the populace, participation means that a large number of citizens voted in favor of electing an official. Deliberation means that some group of officials deliberated about which policies to impose. Democratic input and output can be participatory, or both can be deliberative. Alternatively, democratic input could be deliberative and output participatory, or vice versa. Process democracy, as we will see, combines a participatory public with a deliberative legislative body.

\section{I Selecting Officials}

In this section, I argue that officials should be selected through an equal participatory, aggregative process, which should vindicate the first part of my argument that democratic theories can be usefully applied to different parts of the democratic process.

The democratic process typically begins with the nomination and selection of political officials, such that the selection of officials is the political process at the furthest causal distance from legislative outcomes. All subsequent parts of the political process can neutralize or alter public input.

I contend that political equality and participation are the most important values for selecting officials; deliberation is important, but it can be sacrificed for the other two values as long as deliberation is institutionalized later in the democratic process. I will argue below that deliberation can be institutionalized during policy choice.

Political equality is critical for justifying the selection of political officials for two reasons. First, politically equal choice procedures treat persons with equal respect, and second, politically equal choice procedures convey public judgments about the equal worth of its citizens.

The first argument begins by recognizing that citizens have equal basic rights to vote and participate in the political process. Citizens have equal rights 
to cause the selection of the officials that govern them, even if their contributions are likely to be miniscule. If officials are not selected by a system that respects equal rights to influence the political process, then that system cannot be said to respect our considered judgment that citizens have equal rights to vote. Perhaps we can allow for restrictions of equal rights later in the democratic process because other values are more important. But those restrictions are plausible primarily because political equality is guaranteed at the beginning of the democratic process.

The second argument for the importance of political equality is that unequal democratic systems convey to some citizens that their government does not believe that their interests are of equal importance to those of more privileged persons. Political inequality can even send the message that political officials and the politically privileged classes do not believe that persons are moral equals. Consequently, violations of political equality send the message that marginalized citizens count for less than others. As Thomas Christiano argues, democratic decision-making should not only realize equality but do so publicly because democratic decision-making treats persons as equal in ways that all can appreciate. ${ }^{22}$ Citizens must be able to see that their government treats them all as equal.

Consider two objections. First, many democratic theorists are more interested forms of political equality that concern equal treatment in policy formation that occurs at the end of the democratic process. But process democracy recognizes political equality in policy choice as well. We can assume, then, that political equality is important both in the input and output stages of democratic choice. Second, some democratic theorists may argue that political equality is undermined by congressional representation on the theory that political equality means that persons must have direct causal impact on policy formation. But since this essay is a work of non-ideal theory and real citizens typically lack the time to formulate and discuss policy positions, feasibility considerations justify representation as a heuristic for implementing policies that most people want.

The selection of political officials must also realize the value of participation. We ordinarily care more about everyone having input into the selection process than generating informed, quality choices, even though we care about quality choices a great deal. We care more about participation for two reasons.

22 See Thomas Christiano, The Constitution of Equality: Democratic Authority and Its Limits. New York: Oxford University Press, p. 95. I grant that democracy needn't convey this message, but that is how real-world democratic cultures receive the message, which is enough for my argument to go through. 
First, participation helps to make political institutions responsive to the interests of everyone. And second, participation helps to sustain descriptive legitimacy ${ }^{23}$ by giving everyone a sense that their input into the political process matters.

While the responsiveness of political institutions to public input is far from perfect, political institutions will be more responsive to the input of citizens if political officials cannot afford to ignore large swathes of the public. ${ }^{24}$ Systems that suppress or fail to encourage participation will be less responsive to the collective will of their citizens.

If we prevent some people from participating in the democratic process, or if people believe that their participation is ineffective, then stressing the need for democratic participation will undermine descriptive legitimacy. If citizens are prohibited or discouraged from participating in the selection of officials and are instead represented by elite deliberators, the chosen officials will not be seen as politically legitimate. Democratic citizens will believe, perhaps rightly, that their basic political rights have been nullified even if someone else represents their views. Citizens may feel as though they have no voice. This felt loss of empowerment could easily undermine the stability of the political order, as citizens will see relatively little reason to abide by legislation passed by officials chosen by someone else. Restrictions on participation may even convey that political elites believe that their input has greater significance than excluded citizens, which can further sow distrust. ${ }^{25}$

There are three main challenges to my claim that the selection of officials can realize the values of participation and equality: concerns about (i) the moral significance of unreconstructed, raw mass public opinion, (ii) the coherence of public opinion, and (iii) the choice of a voting rule that reflects the will of the people.

23 I understand descriptive legitimacy as the property a democratic state possesses when its subjects believe that the state has the right to rule. This is in contrast to normative legitimacy, which is the property that a democratic state possesses when it is permitted to create in its subjects a duty to comply with its coercive dictates.

24 For a recent discussion of the responsiveness of democracy, though with a focus on the tie between economic inequality and responsiveness, see Gilens, Martin. (2012). Affluence \& Influence: Economic Inequality and Political Power in America. Princeton: Princeton University Press. For another challenge to the responsiveness of democratic decision-making, see Achen, Christopher and Larry Bartels. (2017). Democracy for Realists: Why Elections Do Not Produce Responsive Government. Princeton: Princeton University Press.

25 This point is complimented rather than challenged by the fact that democratic policy outputs may matter more for justification and legitimacy than democratic inputs. 
(i) The first objection holds that people should not be coerced as a result of a process that is based primarily on uninformed, irrational, and bigoted groups of people, like much of the voting populace. ${ }^{26}$ This problem, I think, is the easiest to solve because the main reason to discount raw mass public opinion is that public opinion might lead to the election of an evil or tyrannical official. But with proper constraints later in the political process, such as rights protections, the power of such officials can be sufficiently limited to make the problem manageable. So even if a bad official supports policy that cannot be justified, further constraints on his power can circumscribe the effect of poor voting.

Of course, bad political officials can find some way around the constraints placed upon them by other branches of government or the constitution. This is true, though it is less of a problem in some democratic systems than others. In the United States, the primary culprit is arguably the office of the presidency, which has accumulated incredible power over the course of the last one hundred years; those powers are easily and frequently abused. ${ }^{27}$ A parliamentary system with the executive chosen by the leading party or coalition might be less vulnerable to this problem. But a better reply is that abuses of power can happen under any system where social trust and descriptive legitimacy break down to the point where the constraints in the constitution are no longer effective, or at least not adequately so. My contention is that trust, descriptive legitimacy, and stability are better maintained when everyone feels that they have some causal input into the political process than by a system where representative persons make decisions for them, even if the decision-making quality of elite deliberators would be greater. My primary source of evidence here is drawn from the literature showing that democratic governments tend to generate more trust in political institutions over time, at least in developed countries. ${ }^{28}$ Again, a participatory system should be more stable and legitimate than a system with low participation and high-quality deliberation because

26 For a review of public political ignorance, see Brennan, Jason. (2011). The Ethics of Voting. Princeton: Princeton University Press, pp. 161-178.

27 Healy, Gene. (2009). The Cult of the Presidency, Updated: America's Dangerous Devotion to Executive Power. Washington, D.C.

28 For a review of the evidence, see Hooghe, Marc. "Trust and Elections." The Oxford Handbook of Social and Political Trust, edited by Eric Uslaner, Oxford University Press, 2018, pp. 617631. The evidence is not decisive because we lack functional epistocracies to compare with democracies, but this is not a defect in my defense of democratic theory, since our positive experience with democracy places the argumentative burden on the person who would abandon democracy for even modest forms of epistocracy. 
citizens will regard a system where they have causal input as morally superior to systems that prevent or discourage them from participation.

(ii) The potential incoherence of mass opinion is a harder problem. A huge amount has been written on the subject, so I will limit myself to a sketch of some prominent positions. William Riker and his followers have insisted that real-world social preferences contain cycles, where individuals have transitive preferences (if $\mathrm{a}>\mathrm{b}$ and $\mathrm{b}>\mathrm{c}$, then $\mathrm{a}>\mathrm{c}$ ), but society has intransitive preferences $\left(a>b\right.$ and $b>c$, but not $c>a$ ) over some list of candidates or issues. ${ }^{29}$ This means that group decision-making requires violating some basic moral or rational conditions on collective choice.

But their attempts to demonstrate the existence of cycles in the real world have been forcefully challenged on empirical grounds. Gerry Mackie has done more than anyone to muddy the Rikerian waters, arguably demonstrating that Riker's examples of important cycles, such as the US election of 1860, are controversial at best, and distortions of the truth at worst. ${ }^{30}$ I think Mackie shows that we have yet to empirically vindicate the Rikerian claim that "on the very most important subjects, cycles may render social outcomes meaningless." ${ }^{31}$ Mackie claims, in contrast, "that the cycles that are alleged to make democracy meaningless are rare" where "the question is not one of logical possibility but rather one of empirical probability."32 Cycles don't happen much. Through his intense scrutiny of common claims of cycles, Mackie has shown that, while Riker could in principle turn out to be correct about the pervasiveness of cycles, there is no decisive, or even weighty, evidence in Riker's favor. I therefore set the issue of the meaningfulness of mass public opinion aside. ${ }^{33}$

The more serious empirical concerns about the value of consulting mass opinion are that the public is systematically biased. ${ }^{34}$ The case for systematic voter bias is based in part on the already-mentioned extensive empirical data demonstrating vast public ignorance on nearly all matters of political importance. There are a number of theories that purport to explain the apparent problematic bias of voters by identifying what voters think that they are doing

29 Riker (1988).

30 Mackie, Gerry. (2003). Democracy Defended. Cambridge: Cambridge University Press., pp. $258-28$ o.

$31 \quad$ Riker (1988, p. 128).

32 Mackie (2003, p. 17).

33 Mackie's critique may be mistaken, but even Riker thinks that consulting mass opinion is important, since mass opinion should be meaningful when it comes to controlling exceptionally bad officials. This consideration should allow democratic theorists tempted by Riker's arguments to nonetheless support choosing officials in a participatory fashion.

34 See Caplan, Bryan. (2007). The Myth of the Rational Voter: Why Democracies Choose Bad Policies. Princeton: Princeton University Press. 
in the ballot box. One influential theory, advanced by Geoffrey Brennan and Loren Lomasky, is that "voting in large-scale elections is disconnected in a fundamental way from citizen preference over electoral outcomes," and that voters in fact vote expressively, that is, to express their affiliation with a value system or some group. ${ }^{35}$ Importantly, since citizens vote expressively, they are much more likely to vote based on ethical considerations, for "expressive behavior will reflect various kinds of ethical and ideological principles that [are] suppressed in the market setting"; this means that expressive political behavior "gives much freer range to ethical considerations." ${ }^{36}$ Yes, voters are ignorant (because they have little incentive to become informed), but an ignorant citizen might vote on factors that could nonetheless have moral and ideological import, such as whether a candidate's expressed policy preferences and political principles match the voter's own values. Such voting may not be problematically biased at all, since much documented political bias concerns certain non-normative beliefs about how policies function; moral beliefs are typically, though not always, another matter.

We should also ask if there are good ways to use deliberation to improve mass opinion. To answer the question, deliberation must be understood in real-world terms. We are not concerned with highly formalized models of deliberation but, rather, with data about how real-world deliberation functions in real democracies. This means that we need to look at evidence that real-world publics that deliberate in certain ways choose systematically better policies (where "better" is understood here as more justified or justifiable) than non-deliberating publics. Unfortunately, the only systematic data that we have on improving opinion through deliberation is from small, focused groups. Fishkin himself has gathered much of this data, which has led him to a moderately favorable view of these focused small-group deliberative bodies, but even he acknowledges that these deliberative bodies may be a poor proxy for public opinion in some cases. ${ }^{37}$ That means we have little data on how to improve the quality of mass opinion. And the prospects for gathering such data are dim because carrying out controlled experiments over the whole public is practically impossible.

To compensate for this lack of data, we might appeal to a priori models of the potential benefits of deliberation, such as the model of deliberation found

35 Brennan, Geoffrey, and Loren Lomasky. (1993). Democracy and Decision: The Pure Theory of Electoral Preference. Cambridge: Cambridge University Press, p. 1.

36 Ibid., p. 16.

37 See Fishkin (2009, pp. 194-6). 
in Hélène Landemore's work. ${ }^{38}$ I worry that Landemore's model is also too far removed from contemporary circumstances to be useful in determining whether democratic procedures for official selection can be justified. However, I think that her model is helpful when trying to determine how policy formation should work. In particular, we can see that an adequately diverse public may be able to arrive at high-quality decisions. That said, there is reason to worry whether the benefits of diversity will survive when a small number of people are randomly sampled from a large diverse group.

Another option is to try to set out and impose ethical principles to govern public deliberation, like Rawls' duty of civility. ${ }^{39}$ These principles often require that citizens discuss important political issues in terms of shareable or accessible reasons that are at least candidates for surviving public scrutiny. If the public can adequately internalize these principles, and compliance will have the effect their advocates hope, this approach may have promise. However, exercising this form of restraint-especially when this means not advocating one's real views or expressing the real values behind them-can impose considerable costs on political participation, which may discourage many citizens from contributing to political life. Many citizens implicitly understand that their causal impact on the political process is miniscule and that makes sincere and informed voting difficult. Placing burdens on political participation could therefore have significant costs. In my view, democratic theorists should instead focus on imposing an ethic on political officials, who have a more substantial causal impact on the political process and who can be held accountable more easily.

(iii) A third concern about the selection of political officials is that determining which voting rules are best for reporting the preferences of citizens is too difficult. As Riker notes, "social choice depends not simply on the wills of individuals, but also on the method used to summarize these wills." ${ }^{40}$ We also know, from social choice theory, that any voting rule that is remotely rational and fair has flaws and is potentially subject to manipulation.

Here are two ways that concerns about voting rules might be addressed. First, we might combine voting rules so that one rule can compensate for the

38 For a recent development of an a priori model of good deliberation, see Landemore, Hélène (2013). Democratic Reason: Politics, Collective Intelligence, and the Rule of the Many. Princeton: Princeton University Press. On her numbers trump ability theorem, see pp. 103-4.

39 Rawls, John. (2005). Political Liberalism. 2nd ed. New York: Columbia University Press, p. 217.

$40 \quad \operatorname{Riker}(1988$, p. 31). 
weaknesses of another. For instance, we could conduct ranked-choice voting and compute the results using both the Borda Count and the Condorcet Rule. In this combined system, each candidate could receive a sum total based on his or her ranking, in accordance with the Borda Count, and each candidate would also be ranked by who wins head-to-head votes, in accordance with the Condorcet rule. If one candidate won in both voting schemes, she would win the election. This is a normatively attractive result, since each voting rule compensates for the decision-theoretic flaws in the other; Borda allows for violations of independence of irrelevant alternatives, but Condorcet does not, whereas Condorcet allows for violations of transitivity, but Borda does not. When the Borda and Condorcet winners differ, we could have an instant runoff rule between the two winners.

Second, we might insist on a system of proportional representation, found in some parliaments, where citizens vote for a party that they like, and then seats of parliament are divided up according to the parties' shares of the vote. This might be an effective alternative to the system of first-past-the-post voting rules, as it would allow for the formation of robust third parties, increasing the diversity of members of the public who see their views represented in the legislature, and lending itself to a more coalition-based model of government, which could compromise on issues that under first-past-the-post lead to acrimony. Moreover, if citizens vote for parties rather than individual candidates, this may lead people to focus on more issues: a system that focuses on parties simplifies choices for citizens by focusing on basic aims more than personalities. And parties can negotiate with one another better if they can rely on their collective capacities, rather than the capacities of individual officials.

Compound social choice rules and parliamentary voting can comprehensively represent the will of the public, because they would enable citizens to express complex preferences about the relative worth of candidates, parties, and policies. By providing outlets for expressing third, fourth, and fifth choices, governments can reflect diverse perspectives.

\section{Policy Choice}

In this section, I argue that policies should be selected through an equal deliberative process, which establishes the second part of my argument that democratic theories can be used to justify different parts of the democratic process.

We turn to the voting procedures that should govern legislation regarding the production of public goods and policies where basic rights are not typically 
at stake. ${ }^{41}$ Examples include the provision of infrastructure, countercyclical policy, and some aspects of social insurance. I argue that policy choice should ensure both political equality and quality deliberation, and so should be prepared to sacrifice participation.

Participation is less essential because policy choice is made by a small number of officials (and perhaps citizens-experts, as I discuss below). Given the small number of officials, each has strong incentive to voice their opinion and vote accordingly, so there is far less need to incentivize participation among officials than among citizens. So institutional design need not focus on guaranteeing participation.

Political equality is critical, however, since we want officials to have equal political power. If they lack equal political power, then one can argue that they do not respect political equality in the official selection process. Citizens choose political officials to represent their views and interests, and so if some political officials have much more power than others, then some citizens may be over-represented and others under-represented. This does not mean that legislative bodies cannot elect leaders, but the legislators must have roughly equal decision-making power to select those leaders.

Since we can sacrifice participation, we can capture the benefits of deliberation. This is welcome; deliberation is critical for producing quality decisions that add to the justification and legitimacy of the policy outputs of the democratic process.

The biggest problem with a deliberative democratic approach to policy choice is that the policy choice process is often plagued by the influence of lobbyists and special interest groups that distort legislation in their favor. This is to be expected for familiar reasons. ${ }^{42}$ Officials are often self-interested, so they can easily be tempted by campaign contributions and the promise of social and economic benefits once they leave office. Furthermore, politicians who are not focused on their self-interest, and who wish to legislate based on other factors, can often be stopped and intimidated by politicians who are "bought and sold."

Rent-seeking can corrupt the legislative process in many ways, not merely through the purchase of legislative votes, but also through legislative tactics

41 In other work, I argue that the protection of rights should realize a different combination of values than either official selection or policy choice. See Vallier, Kevin. (2020). Trust in a Polarized Age. New York: Oxford University Press.

42 See the literature reviews on the topics of rent-seeking and the inefficiencies of bureaucracy in Mueller, Dennis. (2003). Public Choice iii. New York: Cambridge University Press, pp. $333-384$. 
like agenda control. ${ }^{43}$ While Mackie has made a convincing case that these tactics are not used as often as one might expect, there are still serious attempts to co-opt the legislative process for the benefit of the few at the expense of the many ${ }^{44}$ The logic of concentrated benefits and dispersed costs will lead to legislation that cannot be justified because such legislation imposes costs on the many to benefit the few, given that the few are more easily organized into coalitions that can apply pressure on legislated officials.

Political scientists and economists have proposed different institutional reforms to limit rent-seeking and corruption, such as supermajority rules and bicameralism..$^{45}$ If the risk of rent-seeking is proportional to the ease of passing new legislation, then because supermajority rules and bicameralism make passing new laws difficult, they will tend to reduce rent-seeking vis-àvis simple majoritarian institutions. However, the claim that rent-seeking and corruption are easier under simple majority systems is controversial, which is why I do not defend the proposal here, nor would it be good to yoke process democracy to one side of this debate.

I do think that one proposal for increasing deliberative quality in policy choice is plausible and attractive enough to explore here, namely the idea of a policy mini-public. A policy mini-public is composed of citizens selected by random sampling and paid a salary over the course of a month or up to half a year to engage in policy review. Members of the mini-public would learn about a particular policy proposal and its costs and benefits; they would then deliberate about, and finally vote on, whether to recommend the policy for ratification. They could be recalled to sign off on changes to their proposals made by political officials. To avoid outside tampering, citizen identities could be kept private, and we could develop appropriate constraints on what and how information is introduced into their deliberations.

Here's how we might use mini-publics in contemporary democratic politics at the national level. ${ }^{46}$ Unique mini-publics would be selected for each piece of major legislation, with a congressional committee deciding what counts as a major piece of legislation. The groups must be small in size if they are to preserve face-to-face discussion. Face-to-face discussion has great benefits that

43 Ibid., pp. 112-114. For a bipartisan look at the problems of rent-seeking, see Lindsey, Brink, and Steven Teles. (2017). The Captured Economy: How the Powerful Enrich Themselves, Slow Down Growth, and Increase Inequality. New York: Oxford University Press.

44 Mackie (2003, pp. 158-172).

45 See Buchanan, James, and Gordon Tullock. (1962). The Calculus of Consent. Ann Arbor, MI: University of Michigan Press, pp. 233-248 on the effects of bicameralism.

46 This is simply one proposal; deliberative democrats have addressed these problems in other ways. 
anonymous discussion lacks, as persons have an incentive to behave in a calm, reasonable, and moral manner. If a group becomes too large, these dynamics are undermined and more unsavory dynamics can take over. To keep the costs of mini-publics under control, there will be only a limited number of mini-publics at work at a time.

Mini-publics will review the policy recommendations of legislators and make their own recommendations public in almost all cases (save national security issues). The recommendations must be public so that citizens can determine whether politicians are following the recommendations of deliberators and hold politicians responsible if they ignore what the deliberators recommend. Then, when a bill is amended, citizens will have the right of review to see whether further review is required. ${ }^{47}$ At no point could the mini-public stop the legislative process, but their recommendations will have substantial effects, since they will be sampled directly from the public.

The hope for mini-publics is that their recommendations will come to be seen as a proxy for the informed consent of the populace. This is because the deliberators will not be career politicians but randomly selected citizens with limited terms and confidential identities. Their recommendations should be capable of acquiring a high degree of democratic legitimacy if they are seen as representing the public as a whole. If mini-publics, as an institution, gain that legitimacy, then when a mini-public endorses a piece of legislation, that should increase the likelihood that it will be ratified and stabilized.

Fishkin's empirical work on microcosmic deliberation gives us reason to hope that policy mini-publics can increase the quality of deliberation. Fishkin has found that citizens almost never have cyclical collective preferences, because deliberation tends to produce single-peaked preferences; he has also found that polarization effects only crop up from time to time. ${ }^{48}$ So some worries about democratic failure appear to be addressed through careful construction of deliberative practices.

However, Fishkin's experiments have one considerable drawback: they tend to cover political issues of minor significance. ${ }^{49}$ In cases where a mini-public could make recommendations about important policies like healthcare policies, or stimulus bills, we can expect a dramatic increase in attempts to manipulate the process. Legislators will try to control the way in which citizen-deliberators are chosen (not unlike attorneys in the jury selection process)

47 Amendments could be limited to avoid overwhelming deliberators.

48 Fishkin (2009, pp. 143-6).

49 Neblo, Michael. (2015). Deliberative Democracy between Theory and Practice. New York: Cambridge University Press, pp. $185^{-9}$ discusses some drawbacks of mini-publics. 
along with the way in which information is presented to them. Legislators and outside groups may try to influence citizen deliberators in the deliberative process, say by sowing division and discord by making racial, gender, class, religious, or cultural differences salient in discussion. They could even promise these deliberators benefits following the process, like private sector jobs based on their policy experience, if they can circumvent anonymity. These threats could delegitimize the mini-publics.

The protections provided by the jury system could be used to resist these forms of tampering. Again, the identities of the deliberators could be withheld from the public and from the majority of legislative officials. For instance, legislators could select moderators, and the moderators alone could be allowed to know the identity of citizens. ${ }^{50}$ This would help to counteract the temptation to pay off deliberators, and so reduce the incidence of corruption.

To avoid biasing the group in favor of one ideological position or group, deliberators would be selected at random. One potential benefit of randomly selected deliberators is that we are likely to end up with a diverse mini-public that is harder to bias in a particular direction. As Landemore has argued, diverse groups can often contribute to good decision-making better than a group of persons with high amounts of ability, so long as deliberation is appropriately structured. ${ }^{51}$ Critically, diversity can trump ability, so deliberators' diversity might compensate for their weak deliberative skills. That said, elite deliberative groups will be small, such that Landemore's numbers-trump-ability theorem may not apply. ${ }^{52}$

One might also worry that the information that deliberators appeal to can be limited or distorted by the political process. And even if politicians did not try to control the flow of information, the media and partisan bias would still corrupt the mini-public members are presented. Thus, the mini-public's deliberation may not be based on good information.

An attractive remedy for this problem is to require deliberators to consult prediction markets for information about which policy proposals are likely to be effective. Prediction markets are structured as follows: Participants in the market bet on the effects of various policies in the future by buying and selling predictions, and so, through supply and demand, affecting the odds offered in the market. Participants without good information will tend to have views that

$5^{\circ}$ It is true that moderators themselves may be selected by special interest groups, and it is hard to guard against that possibility. Perhaps moderators could be placed under a fairly strict set of procedural rules, acting only in very specific, routinized ways, which could limit the point in corrupting the moderator nomination process.

$51 \quad$ Landemore (2013, pp. 102-4).

52 Ibid., p. 104. 
are randomly distributed across the relevant range of predictions, and so we can expect their views to cancel one another out. But people with good information will tend to tilt the market in favor of their position and against others. So, prediction markets serve as good information aggregators. They are surely imperfect, but they could dramatically improve the quality of information available to deliberators. As Robin Hanson argues, prediction markets are our most epistemically effective method of gathering information. ${ }^{53}$ Further, prediction markets have the advantage of anonymity of recommendation, which means that citizen-deliberators can receive information that is untainted by the celebrity and charisma of a popular cultural figure. Landemore has complained that prediction markets are not themselves a political decision-making mechanism, but prediction markets can still be a useful supplement for citizen deliberation. ${ }^{54}$ Philip Tetlock has argued that a few people are "superforecasters" who can beat prediction markets, but there is no reason why citizen-deliberators cannot listen to superforecasters as well..$^{55}$

I grant that deliberation has flaws, both due to discourse failure within the group and due to attempts to influence the group from the outside. But the incentives of mini-publics, combined with Fishkin's long experience with such small-group deliberation, gives us reason to hope that consulting elite deliberators could help to minimize the errors produced by the constitutional rules governing the productive policy process. We won't eliminate error, but we can elevate deliberative equality and tie the ratification of legislation to high-quality deliberation.

A final concern is that legislators will ignore policy mini-publics if the mini-publics go against public opinion. ${ }^{56}$ Since politicians often genuinely care about their constituents' untutored views, they may have a strong incentive to ignore the mini-public, since it is constituents as a whole who vote. And since the mini-public has no binding political power, it would have no way to successfully fight back. In reply, we can only hope that members of the public can recognize that, because the mini-public is randomly selected and knows more than they do, they can treat the mini-public as representing their considered views. Citizens often approach their representatives in this way, only sometimes blaming them for voting differently than they would like to on complex matters. The promise is that the mini-public will be seen more like the public

53 Hanson, Robin. (2013). "Shall We Vote on Values, But Bet on Beliefs?" Journal of Political Philosophy 21, 151-178.

54 Landemore (2013, pp. 173-184).

55 Tetlock, Philip, and Dan Gardner. (2016). Superforecasting: The Art and Science of Prediction. Broadway Books.

$5^{6}$ I thank David Estlund for encouraging me to address this concern. 
than elected representatives and will inherit some moral authority in that way. If this is not convincing, we might be able to get mini-publics widely recognized as serving Congress in an advisory role; that would create an expectation that Congress will listen to the mini-publics without raising concerns about the mini-publics having equal authority with Congress itself. ${ }^{57}$

We also defer to the judgments of juries in civil and criminal trials, and juries are akin to mini-publics. This shows that many democracies are already prepared to allow a group of randomly selected, representative peers to make important decisions. It is true that, in certain high-profile cases where the public pays close attention, jurors are sometimes blamed and attacked for going against public opinion. But data on mini-publics gives us reason to think that mini-publics can increase the quality of deliberation in the formation of public policy.

An underemphasized force that can lead legislators to listen to mini-publics is if they know that citizens trust them to listen and act upon what citizens want. Citizens may have a high level of political trust on the grounds that, in the past, political officials have tended to produce good outcomes in accord with fair and uncorrupt processes. If a polity has high political trust, then legislators may feel as though they owe it to citizens to listen to the voices of those who best represent them. ${ }^{58}$

Another way to increase the influence of mini-publics is to require that they list the reasons and arguments they find most convincing, as Michael Neblo proposes. ${ }^{59}$ Listing reasons and arguments would provide evidence that the mini-public's recommendations are reflective and careful, it would generate more information for the public to consider, and it might create trust by revealing to the public that the deliberators are good-willed, transparent, and informed. It would also allow ordinary citizens who addressed those arguments in their own public comments to feel as though they were participants in the mini-public. It could help nonparticipants decide which policies and candidates to endorse. Politicians would respond to the mini-public's reasons and arguments, especially if the public expects them to. Politicians will also have a better sense for how and why some policies have legitimacy in the eyes of the public, since the mini-publics would be based on random sampling.

57 I thank Jenny Lambe for this point.

$5^{8}$ For an account of the role of political trust in facilitating quality democratic decisionmaking, see Hetherington, Mark. (2015). Why Washington Won't Work: Polarization, Political Trust, and the Governing Crisis. Chicago: University of Chicago Press.

59 See Neblo (2015, p. 187). 
I have argued that official selection can be justified if it realizes the values of political equality and participation. I then argued that policy choice can be justified if it realizes the values of political equality and deliberation. The democratic process is thereby justified conjunctively by justifying each stage of the process.

But now consider two objections. First, one might complain that process democracy cannot adequately realize different democratic values simply by realizing different values at each stage because each stage has weaknesses as well as strengths. Accordingly, the value of the democratic process on the whole cannot be greater than the mixed value of its parts. To combat this important objection, consider that the realization of democratic values diminishes at the margin. Ensuring that $6 \circ \%$ of citizens vote takes proportionally less effort than ensuring that an additional $30 \%$ of citizens vote. Thus, the returns to increasing participation diminish. The same is true of deliberation; each additional unit of deliberation is worth a bit less and costs a bit more than the previous unit. Thus, a system that focuses only on realizing participation will have less overall value than a system that focuses on both deliberation and participation because a participation-focused democratic process replaces a relatively more valuable and less costly unit of deliberation with a relatively less valuable and more costly unit of participation. The same problem arises for a deliberation-focused democratic process. It is better to have a democratic process that realizes, to put it somewhat artificially, one unit of participation and two units of deliberation rather than three units of deliberation, or one unit of deliberation and two units of participation rather than three units of participation. In this way, a complex democratic whole that realizes a multiplicity of democratic values will have more overall value than a simple democratic whole due to the logic of diminishing returns to political values.

Second, a critic could worry that only one stage of the democratic process is in the justificatory driver's seat; that is, perhaps one stage of the democratic process is much more important for justifying democracy than another stage. To see this, consider that democrats want finality in decision-making, and so will want one institution to prevail in cases of conflict. Once we face the possibility of conflict between stages, we will be forced to decide which values are important for justifying democracy. For instance, one might argue that policy choice is far more important for justifying democracy than selecting officials because we want good policies more than appropriately selected officials. So we will want to structure a democratic process to ensure that the right policies 
are chosen even if that means sacrificing a better process for selecting political officials.

Whether stages of the democratic process will conflict with one another is an empirical matter; if the risk of conflict is low, then the question of finality need not be settled in practice. Nonetheless, theorists will still wonder which stages matter more. I cannot fully answer this question without appealing to a fully general criterion of legitimacy, such as a liberal principle of legitimacy that permits all and only those policies that can be justified by appeal to public reasons. ${ }^{60}$ But for our purposes, we do not need to decide whether official selection or policy choice is the real source of legitimacy because we can simply allow for different weightings of each process without giving finality to either process. Institutional design can proceed by giving relatively more weight, say, to justified policy choice than to justified official selection. Both stages matter for justifying democracy even if one stage matters more.

\section{Process Democracy and Legitimacy}

I understand process democracy as the conjunction of stages of the democratic process where each stage realizes a unique, if limited, mix of democratic values. In this essay, I have defended a process democratic approach to justifying democracy. But process democracy also provides an attractive conception of legitimacy, that is, an account of when the state can obligate citizens to obey its dictates. Process democracy claims that a democratic process is legitimate to the extent that each of its stages adequately realizes its characteristic values. The selection of officials is legitimate when it is adequately equal and participatory; so official selection imposes a duty on citizens to abide by the outcome of an adequately equal and participatory election. Policy choice is legitimate when legislators have roughly equal decision-making power and they draw on high-quality deliberation; policy formation can then obligate officials to comply with the vote and obligate citizens as a whole to comply with the ratified policy. A democratic state is legitimate to the extent that its constituent decision-making processes realize their respective values.

Contrast this compound account of legitimacy with two of the most familiar and popular accounts of democratic legitimacy: deliberative democracy (as a theory of legitimacy, not justification) and aggregative democracy. Deliberative democracy holds that democratic decisions are legitimate when they are the

6o Rawls (2005, p. 137). 
outcome of certain structured, egalitarian forms of deliberation. ${ }^{61}$ Aggregative democracy ascribes legitimacy to democratic decisions when the judgments of citizens are aggregated according to attractive conditions, such as the Pareto principle. ${ }^{62}$

Process democracy appropriates the strengths of both deliberative and aggregative approaches because both deliberation and aggregation are essential for legitimizing different parts of the democratic process. The selection of political officials more or less corresponds to the approach of aggregative democrats. We take raw mass opinion and use normatively attractive voting rules to convert raw mass opinion into a morally compelling candidate choice procedure that ensures that candidates are in some sense chosen by the people. Thus, appropriate aggregation is essential for legitimizing the selection of officials; the other part of legitimizing the selection of officials is ensuring that everyone has equal input into the process, which aggregative democrats also accept.

Deliberative democrats often complain that aggregative democrats take citizen judgments as given, rather than understanding citizen judgments as in need of appropriate shaping by the political process; this criticism is supposed to make aggregative approaches inappropriate, or at least incomplete. ${ }^{63}$ Process democracy is not vulnerable to this charge because it does not take preferences as given. The formation of preferences is an open process that can be appropriately formed by principles of deliberative restraint and institutionally structured discussion. Further, and more importantly, I side with deliberative democrats in insisting that high-quality deliberation is essential for legitimizing policy choice. Policies must be imposed for high-quality deliberative processes to be legitimate.

In sum, then, process democracy combines the attractions of aggregative and deliberative democracy and avoids their flaws by capturing at least part of the value that the other democratic theory lacks. Given that process democracy possesses the strengths of two accounts of the justification of democracy, and two accounts of democratic legitimacy, it is an attractive, new approach to democratic theory.

61 For classic works of deliberative democracy, see ft. i.

62 Rather, aggregative democrats appear to ascribe legitimacy on this basis; though in reality, they tend to say little if anything about their normative assumptions. I thank [redacted] for discussion about how exactly one comes to be called an aggregative democrat.

63 For an early version of the criticism, see Cohen, Joshua. (1991). "Review of Robert Dahl's Democracy and Its Critics." Journal of Politics 53, 221-225, though I think this misfires as a criticism of Dahl, who is not obviously an aggregative democrat. For an overview of the deliberative democratic narrative, see Bohman and Rehg (1998, pp. ix-xiii). 


\section{Acknowledgements}

I am grateful to a number of careful readers of this chapter for their comments, including David Estlund, Joshua Miller, Enzo Rossi, Alex Guerrero, Alexander Cohen, Scott Simmons, Eduardo Martinez, a number of anonymous referees, and workshop participants at Brown University in 2017 and in Washington, D.C. in 2020.

\section{Biographical Note}

Kevin Vallier is an Associate Professor of Philosophy at Bowling Green State University. He is the author of Liberal Politics and Public Faith:Beyond Separation (Routledge 2014) and Must Politics Be War? Restoring Our Trust in the Free Society (Oxford University Press 2019). His research interests concern the liberal tradition broadly, including liberal political economy, democratic theory, public reason liberalism, descriptive theories of liberal order and political stability, the role of social trust in liberal order, and the proper place of religion in liberal societies. His next book, Trust in a Polarized Age (Oxford University Press 2020) focuses on the relationship between trust, polarization, and liberal democracy. 